Atmos. Chem. Phys. Discuss., 10, 19175-19194, 2010

www.atmos-chem-phys-discuss.net/10/19175/2010/

doi:10.5194/acpd-10-19175-2010

(c) Author(s) 2010. CC Attribution 3.0 License.

\title{
A meridional structure of static stability and ozone vertical gradient around the tropopause in the Southern Hemisphere extratropics
}

Y. Tomikawa ${ }^{1,2}$ and T. Yamanouchi $i^{1,2}$

${ }^{1}$ National Institute of Polar Research, Tokyo, Japan

${ }^{2}$ The Graduate University for Advanced Studies, Kanagawa, Japan

Received: 17 June 2010 - Accepted: 11 August 2010 - Published: 13 August 2010

Correspondence to: Y. Tomikawa (tomikawa@ nipr.ac.jp)

Published by Copernicus Publications on behalf of the European Geosciences Union.

$\mathrm{N}^{2}$ and $d \mathrm{O}_{3} / d z$ around the $\mathrm{SH}$ tropopause

Y. Tomikawa and T. Yamanouchi

Title Page

Abstract

Introduction

Conclusions

References

Tables

Figures

14

$\triangleleft$

Back

Full Screen / Esc

Printer-friendly Version

Interactive Discussion 


\section{Abstract}

An analysis of the static stability and ozone vertical gradient in the ozone tropopause based (OTB) coordinate is applied to the ozonesonde data at 10 stations in the Southern Hemisphere (SH) extratropics. The tropopause inversion layer (TIL) with a static

5 stability maximum just above the tropopause shows similar seasonal variations at two Antarctic stations, which are latitudinally far from each other. Since the sunshine hour varies with time in a quite different way between these two stations, it implies that the radiative heating due to solar ultraviolet absorption of ozone does not contribute to the seasonal variation of the TIL. A meridional section of the static stability in the OTB coordinate shows that the static stability just above the tropopause has a large latitudinal gradient between $60^{\circ} \mathrm{S}$ and $70^{\circ} \mathrm{S}$ in austral winter because of the absence of the TIL over the Antarctic. It is accompanied by an increase of westerly shear with height above the tropopause, so that the polar-night jet is formed above this latitude region. This result suggests a close relationship between the absence of the TIL and

15 the stratospheric polar vortex in the Antarctic winter. A vertical gradient of ozone mixing ratio, referred to as ozone vertical gradient, around the tropopause shows similar latitudinal and seasonal variations with the static stability in the SH extratropics. In a height region above the TIL, a small ozone vertical gradient in the midlatitudes associated with the Antarctic ozone hole is observed in a height region of the subvortex but not around the polar vortex. This is a clear evidence of active latitudinal mixing between the midlatitudes and subvortex.

\section{Introduction}

Recent studies have shown that a stable layer with a static stability larger than usual stratospheric values exists just above the extratropical tropopause throughout the year (Birner et al., 2002; Birner, 2006; Randel et al., 2007b; Bell and Geller, 2008). This stable layer was first identified by an average in a vertical coordinate relative to the

\section{$\mathrm{N}^{2}$ and $d \mathrm{O}_{3} / d z$ around the $\mathrm{SH}$ tropopause}

Y. Tomikawa and T. Yamanouchi

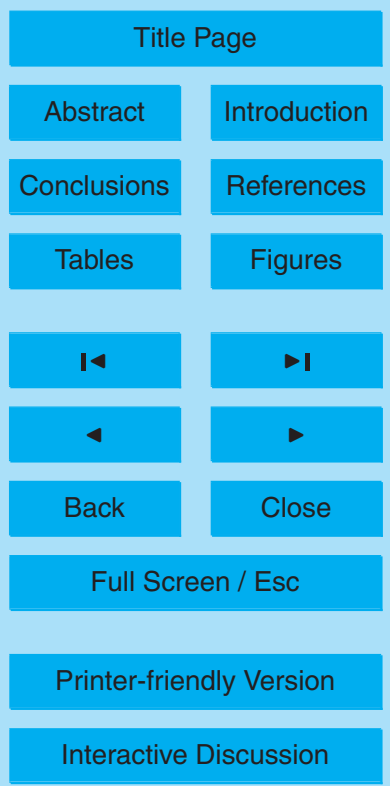


thermal tropopause and called a tropopause inversion layer (TIL) (Birner et al., 2002). The static stability in the TIL shows large seasonal and latitudinal variations with the largest value in the summer polar region (Randel et al., 2007b; Grise et al., 2010).

The thermal tropopause is defined by a transition of temperature lapse rate from a 5 large tropospheric value to a small or negative stratospheric value (WMO, 1957). Since the thermal tropopause can be determined only by a vertical distribution of temperature, it has been used as a simple and useful definition of the tropopause mainly in the midlatitudes. Over the Antarctic, lower stratospheric temperature in austral winter and spring is extremely low, so that the temperature lapse rate does not change so much 10 as that in the midlatitudes and the thermal tropopause is not clearly defined (Highwood et al., 2000; Roscoe, 2004). On the other hand, a transition of ozone concentration from a tropospheric small value to a stratospheric large value is observed even in the Antarctic winter and spring, which indicates that the tropopause can be defined using ozone concentration (i.e., ozone tropopause, cf. Bethan et al. (1996)). Tomikawa 15 et al. (2009) first described the characteristics of the TIL over the Arctic and Antarctic in a vertical coordinate relative to the ozone tropopause and indicated that the TIL disappears in the Antarctic winter and spring.

Several formation and maintenance mechanisms of the extratropical TIL have been suggested in the previous studies. Wirth (2003) suggested that upper-level anticyclones are accompanied by strong TILs and occupy larger area than cyclones, which leads to a TIL in the climatological mean. Birner (2010) demonstrated that the vertical gradient of residual vertical velocity enhances the static stability just above the tropopause and forms the TIL especially in the winter midlatitudes. Randel et al. (2007b) showed that large vertical gradients of ozone and water vapour concentrations around the tropopause contribute to the formation of the TIL through longwave and shortwave radiations using radiative transfer calculations. Focusing on the polar region, several recent studies indicated that a vertical distribution of water vapour around the tropopause significantly varies with season and plays a primary role for the seasonal variation of static stability in the TIL (Kunz et al., 2009; Randel and Wu, 2010;

\section{$\mathrm{N}^{2}$ and $d \mathrm{O}_{3} / d z$ around the $\mathrm{SH}$ tropopause}

Y. Tomikawa and T. Yamanouchi

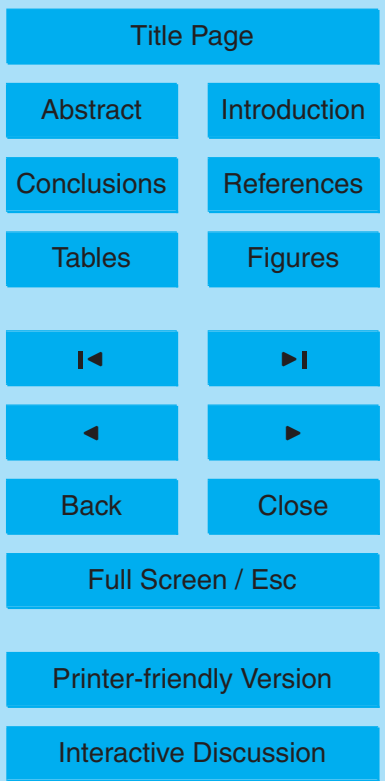


Birner, 2010).

The extratropical TIL is often collocated with the extratropical tropopause transition layer (ExTL), which is defined as a region with both the tropospheric and stratospheric signatures of long-lived chemical constituents (Pan et al., 2004; Hegglin et al., 2009).

5 The vertical distributions of long-lived chemical constituents such as ozone and water vapour have a significant impact on the TIL through radiative processes as mentioned in the previous paragraph. At the same time, since the enhanced static stability in the TIL suppresses the vertical mixing across the tropopause, the TIL itself controls the vertical distributions of chemical constituents. Miyazaki et al. (2010b) investigated 10 a relationship between the TIL and ExTL using a high-resolution general circulation model (GCM) and showed that they interact with each other through dynamic and thermodynamic processes (see also Miyazaki et al. (2010a)). Therefore, it is essential to examine the static stability and material distribution together for understanding the formation and maintenance mechanisms of the TIL and ExTL.

15 In this study, vertical and latitudinal structures of the static stability and vertical gradient of ozone mixing ratio are examined using ozonesonde data in the Southern Hemisphere $(\mathrm{SH})$ extratropics. In order to demonstrate their seasonal variations including winter and spring over the Antarctic, we extend the analysis using the ozone tropopause based coordinate into the whole extratropical region in the $\mathrm{SH}$. This anal20 ysis captures well latitudinal and vertical structures of the static stability and vertical gradient of ozone mixing ratio in the $\mathrm{SH}$ extratropics. The object of this study is to discuss a radiative role of ozone for the formation of the TIL, a relationship between the TIL and stratospheric polar vortex, and outflow of ozone-depleted air from the Antarctic ozone hole into midlatitudes. The remainder of this paper is organized as follows.

25 Section 2 describes details of the ozonesonde data and ozone tropopause based coordinate used in this study. Latitudinal and seasonal variations of the static stability and vertical gradient of ozone mixing ratio obtained in the OTB coordinate are presented and discussed in section 3. Concluding remarks are given in Sect. 4.

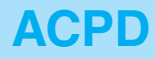

10, 19175-19194, 2010



Y. Tomikawa and T. Yamanouchi

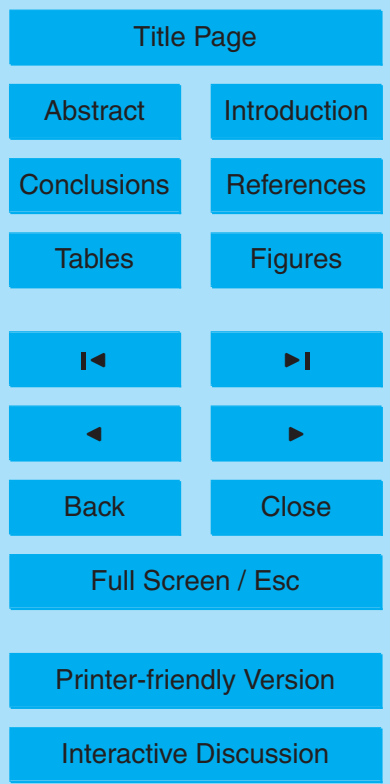




\section{Data and methodology}

Routine ozonesonde observation data at 10 stations in the $\mathrm{SH}$ extratropics were obtained from World Ozone and Ultraviolet Radiation Data Centre (WOUDC) and Network for the Detection of Atmospheric Composition Change (NDACC). They have vertical

5 resolutions high enough to represent the sharp vertical structure of the static stability and ozone mixing ratio around the tropopause. Details of the ozonesonde data are given in Table 1. Precision and accuracy of ozonesonde observations are discussed in Komhyr et al. (1995).

Since the thermal tropopause over the Antarctic during austral winter and spring is not well defined (Roscoe, 2004), it is more appropriate to use the ozone tropopause as the definition of the tropopause there (Tomikawa et al., 2009). The ozone tropopause is defined as the lowest level satisfying the following three conditions (Tomikawa et al., 2009; Bethan et al., 1996):

- Vertical gradient of ozone mixing ratio exceeds $60 \mathrm{ppbv} \mathrm{km}^{-1}$.

15 - Ozone mixing ratio is greater than 80 ppbv.

- Ozone mixing ratio in a layer from $500 \mathrm{~m}$ to $1500 \mathrm{~m}$ above the tropopause exceeds 110 ppbv.

The ozone tropopause height agrees well with the thermal tropopause height within a range of several hundred meters in the $\mathrm{SH}$ midlatitudes (not shown). Thus the ozone tropopause can be used as a surrogate of the thermal tropopause in the whole extratropical region.

In order to establish a sharp vertical structure of the static stability and ozone mixing ratio around the tropopause, the ensemble average in the vertical coordinate relative to the ozone tropopause is used in this study following Tomikawa et al. (2009), which is called the ozone tropopause based (OTB) average. The distribution obtained by the OTB average is vertically shifted by the mean tropopause height in a similar fashion

\section{$\mathrm{N}^{2}$ and $d \mathrm{O}_{3} / d z$ around the $\mathrm{SH}$ tropopause}

Y. Tomikawa and T. Yamanouchi

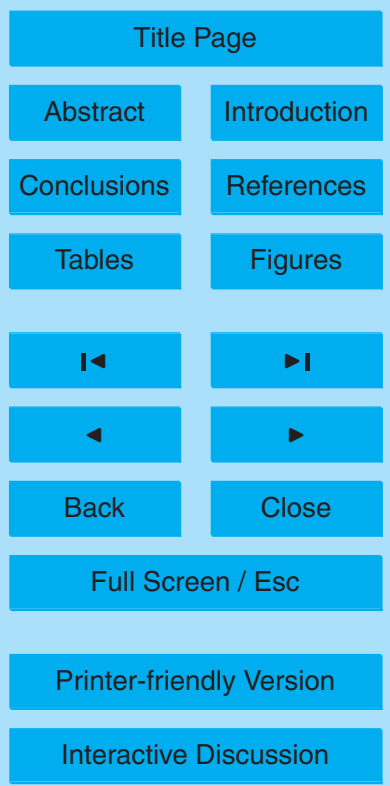


with Birner et al. (2002) and Birner (2006). This operation enables us to investigate a meridional variation of the tropopause characteristics without losing its sharp vertical structure.

\section{Results}

\section{3.1 Seasonal variation of the TIL over the Antarctic}

Figure 1 shows seasonal variations of monthly-mean Brunt-Väisälä frequency squared $\left(\mathrm{N}^{2}\right)$ at Neumayer and South Pole in the OTB coordinate. $\mathrm{N}^{2}$ just above the tropopause at Neumayer and South Pole are maximized in February and March and minimized in August and September. They show nearly the same seasonal variations in terms 10 of their timing and strength in spite of their latitudinal separation of about $20^{\circ}$. Both of these two stations are located inside the stratospheric polar vortex during austral winter, so that their dynamical condition is similar. However, the sunshine hour around the tropopause is much different between Neumayer and South Pole because of their latitudinal separation.

Figure 2 shows seasonal variations of the sunshine hours at an altitude of $10 \mathrm{~km}$ over Neumayer and South Pole. While the sunshine hour at Neumayer changes gradually from its maximum to minimum for about five months, that at South Pole changes in a few days between 0 and $24 \mathrm{~h}$. The diabatic heating due to solar ultraviolet absorption of ozone is proportional to the sunshine hour. Thus, if the ozone heating contributes to the formation and seasonal variation of the tropopause inversion layer (TIL) over the Antarctic, the TIL at Neumayer and South Pole should exhibit different seasonal variations. Little difference of the seasonal variations of the TIL between Neumayer and South Pole implies that the ozone heating does not have a significant contribution to the formation and seasonal variation of the TIL over the Antarctic. This inference is consistent with the recent studies that emphasized the radiative role of water vapour for the seasonal variation of the TIL in the polar region (Kunz et al., 2009; Birner, 2010;



10, 19175-19194, 2010

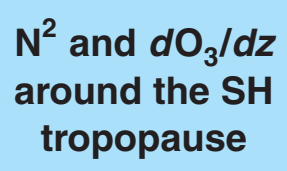

Y. Tomikawa and

T. Yamanouchi






\subsection{Meridional structure of the TIL in the SH extratropics}

Figure 3 shows latitude-height sections of seasonal-mean $\mathrm{N}^{2}$ during austral summer (December, January, and February) and winter (June, July, and August) in the OTB co5 ordinate. Arrows on the top axes represent the station latitudes. Since the ozonesonde data at McMurdo $\left(77.9^{\circ} \mathrm{S}\right)$ are available only in austral winter and spring, Fig. $3 a$ is drawn without the data at McMurdo. In general, the data at each station are not necessarily representative of the corresponding latitude. However, longitudinal variations of $\mathrm{N}^{2}$ in the extratropical TIL are small compared to its latitudinal variations (Randel et al., 10 2007b; Grise et al., 2010), so that the longitudinal variations of $\mathrm{N}^{2}$ and vertical gradient of ozone mixing ratio are not taken into account in this study.

The ozone tropopause in austral summer, which is shown by the thick solid line in Fig. 3a, is located around $13 \mathrm{~km}$ over Broadmeadows $\left(37.7^{\circ} \mathrm{S}\right)$ and quickly drops down to about $9 \mathrm{~km}$ around $65^{\circ} \mathrm{S}$. This region with a large latitudinal gradient of the ozone tropopause height is close to the core of the subpolar jet in austral summer (Tomikawa et al., 2006). On the other hand, the ozone tropopause height becomes nearly constant in a latitude region poleward of $65^{\circ} \mathrm{S}$. Enhanced $\mathrm{N}^{2}$ just above the tropopause corresponding to the TIL is observed in a region poleward of the subpolar jet and its magnitude becomes larger with latitude. The strong TIL in the summer polar 20 region has been reported in the previous studies (Birner, 2006; Randel et al., 2007b; Grise et al., 2010).

The ozone tropopause height in austral winter is nearly constant or slightly decreases with latitude (Fig. 3b). This feature is clearly different from the thermal tropopause, which is higher in the polar region than in the midlatitudes (i.e., Birner, 2006; Randel

et al., 2007b; Grise et al., 2010). The higher thermal tropopause misidentifies stratospheric air with high ozone concentration as tropospheric air. Thus, a usage of the ozone tropopause as the tropopause definition is most appropriate to describe the tropopause characteristics in the polar region (Tomikawa et al., 2009).

19181
10, 19175-19194, 2010

\section{$\mathrm{N}^{2}$ and $d \mathrm{O}_{3} / d z$ around the $\mathrm{SH}$ tropopause}

Y. Tomikawa and T. Yamanouchi

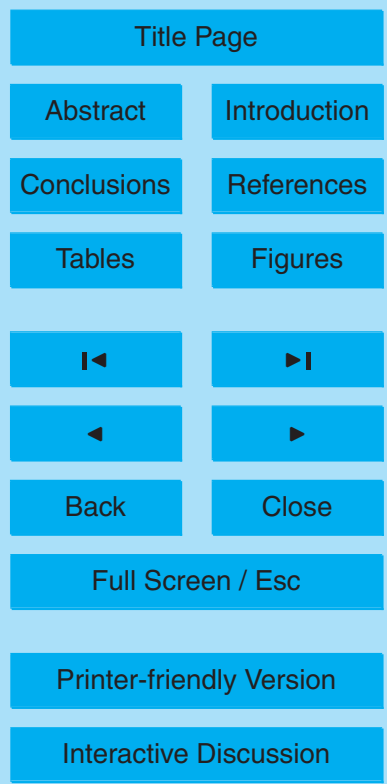


During austral winter, $\mathrm{N}^{2}$ maximum just above the tropopause corresponding to the TIL is observed in the midlatitudes but does not appear in the polar region, which is consistent with Tomikawa et al. (2009). $\mathrm{N}^{2}$ just above the tropopause quickly decreases from $60^{\circ} \mathrm{S}$ to $70^{\circ} \mathrm{S}$ and becomes nearly constant in a region poleward of about $70^{\circ} \mathrm{S}$. 5 A large meridional gradient of $\mathrm{N}^{2}$ between $60^{\circ} \mathrm{S}$ and $70^{\circ} \mathrm{S}$ just above the tropopause is accompanied by increase of westerly shear with height through the following relationship (cf. Birner, 2006):

$\frac{\partial^{2} \bar{u}}{\partial z^{2}} \approx-\frac{1}{f} \frac{\partial N^{2}}{\partial y}$

where $\bar{u}$ is zonal-mean zonal wind and $f$ is the Coriolis parameter. This equation 10 is approximately obtained as a vertical derivative of the thermal wind equation. The enhanced westerly shear above the tropopause forms the polar-night jet in the winter stratosphere. Therefore, the absence of the TIL in the winter polar region is closely related to the polar-night jet.

\subsection{Vertical gradient of ozone mixing ratio in the SH extratropics}

15 Both of potential temperature and ozone mixing ratio are conserved following air parcel motions without any nonconservative processes. It means that conservative processes such as advection due to meridional circulation act on them in the same way. Thus a usage of these conserved quantities is useful for isolating conservative from nonconservative processes. Since $\mathrm{N}^{2}$ is nearly proportional to the vertical gradient of potential temperature, we examine the vertical gradient of ozone mixing ratio for comparison with $\mathrm{N}^{2}$ in this subsection.

Figure 4 shows time-height sections of monthly-mean vertical gradient of ozone mixing ratio, hereafter referred to as ozone vertical gradient, at Neumayer and Lauder in the OTB coordinate. The ozone vertical gradient just above the tropopause at Neumayer is maximized in austral summer and minimized in winter. This seasonal variation

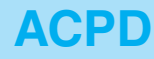

10, 19175-19194, 2010

\section{$\mathrm{N}^{2}$ and $d \mathrm{O}_{3} / d z$ around the $\mathrm{SH}$ tropopause}

Y. Tomikawa and T. Yamanouchi




is synchronized with that of $\mathrm{N}^{2}$. On the other hand, a small value of ozone vertical gradient appears above $12 \mathrm{~km}$ in September and descends with time until April (cf. Sato et al., 2009). This is due to the Antarctic ozone hole. The ozone vertical gradient just above the tropopause at Lauder is maximized in austral winter and minimized in 5 summer. This seasonal variation is synchronized with that of $\mathrm{N}^{2}$ (not shown), but in an opposite phase to that at Neumayer. A small value of ozone vertical gradient is observed between 12 and $15 \mathrm{~km}$ except for austral winter, which is similar to that at Neumayer.

Finally, latitude-height sections of seasonal-mean ozone vertical gradient in austral 10 winter and spring are shown in Figure 5. The ozone vertical gradient just above the tropopause in austral winter decreases from $60^{\circ} \mathrm{S}$ to $70^{\circ} \mathrm{S}$ and becomes nearly constant in a region poleward of $70^{\circ} \mathrm{S}$. This latitudinal variation of the ozone vertical gradient is similar to that of $\mathrm{N}^{2}$. In austral spring, a small ozone vertical gradient due to the Antarctic ozone hole is observed above $11 \mathrm{~km}$ in a region poleward of $70^{\circ} \mathrm{S}$. An5 other region with a small ozone vertical gradient is observed in a region equatorward of $70^{\circ} \mathrm{S}$, but its height range is limited to below $14 \mathrm{~km}$. Above $15 \mathrm{~km}$ in this latitude region, the ozone vertical gradient is much larger than that in the polar region. This result indicates that, while the ozone-depleted air in the Antarctic polar vortex is isolated from the midlatitudes above $15 \mathrm{~km}$, it leaks from the polar region to the midlatitudes below $2014 \mathrm{~km}$. Since the residual circulation in the lower stratosphere during austral spring is poleward (Rosenlof and Holton, 1993), the leak of ozone-depleted air is due to the latitudinal mixing rather than the meridional circulation. The small ozone vertical gradient in the midlatitudes is still observed in austral summer (not shown).

A height region between 14 and $15 \mathrm{~km}$ in the midlatitudes is roughly correspond25 ing to isentropes between 380 and $400 \mathrm{~K}$. Haynes and Shuckburgh (2000) indicated that the Antarctic polar vortex during austral spring was permeable to a large-scale isentropic mixing below a 380-K isentrope (see also Chen, 1994). Mclntyre (1995) showed that a similar permeable region also existed in the Arctic lower stratosphere using the airborne lidar observation of aerosol and called it a subvortex. Our study

\section{$\mathrm{N}^{2}$ and $d \mathrm{O}_{3} / d z$ around the $\mathrm{SH}$ tropopause}

Y. Tomikawa and T. Yamanouchi

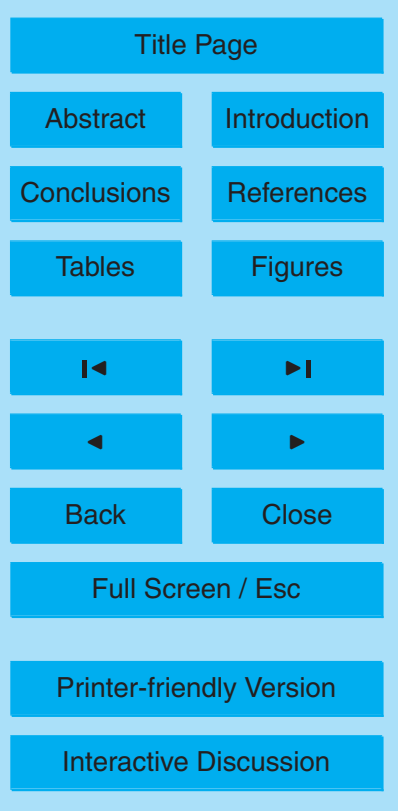


clearly demonstrated that the latitudinal mixing in the subvortex region transported the ozone-depleted air in the Antarctic polar vortex into the midlatitudes and changed the ozone mixing ratio in the midlatitude lower stratosphere (cf. Reid et al., 1998). In addition, the small ozone vertical gradient above the midlatitude tropopause remains 5 until austral summer or fall, which implies that the Antarctic ozone hole affects the midlatitudes even after spring. On the other hand, the midlatitude lower stratosphere is susceptible to the intrusion of ozone-poor air from the tropical upper troposphere (Chen et al., 1994; Randel et al., 2007a; Pan et al., 2009). Therefore, a separation of air parcels with tropical and polar origins is necessary for quantitative evaluation of the 10 impact of the Antarctic ozone hole on the midlatitude ozone loss.

\section{Conclusions}

An analysis of the static stability and ozone vertical gradient in the ozone tropopause based (OTB) coordinate was applied to the ozonesonde data at 10 stations in the Southern Hemisphere $(\mathrm{SH})$ extratropics. This is the first comprehensive study of the

15 TIL and ozone distribution in the SH extratropics using the OTB coordinate. It captured a sharp vertical structure of the static stability and ozone vertical gradient around the extratropical ozone tropopause and clearly showed their latitudinal and seasonal variations. Seasonal variations of the static stability just above the tropopause are quite similar between Neumayer $\left(70.7^{\circ} \mathrm{S}\right)$ and South Pole $\left(90^{\circ} \mathrm{S}\right)$ in spite of their latitudinal separation of about $20^{\circ}$. On the other hand, the sunshine hours around the tropopause vary with time in a quite different way between Neumayer and South Pole. Since the radiative heating associated with solar ultraviolet absorption of ozone is proportional to the sunshine hour, this result implies that the ozone heating does not contribute to the seasonal variation of the static stability in the TIL over the Antarctic.

25 In austral summer, the tropopause inversion layer (TIL) is observed in a region poleward of the subpolar jet and becomes strongest over the Antarctic. In austral winter, the static stability just above the tropopause is maximized in the midlatitudes and quickly



10, 19175-19194, 2010

\section{$\mathrm{N}^{2}$ and $d \mathrm{O}_{3} / d z$ around the $\mathrm{SH}$ tropopause}

Y. Tomikawa and T. Yamanouchi

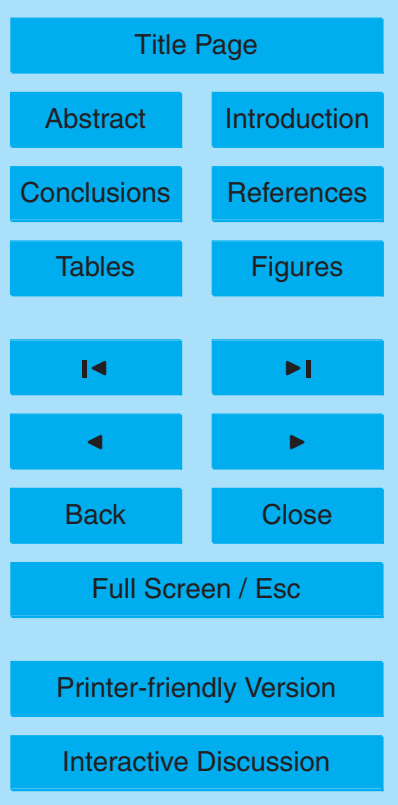


decreases from $60^{\circ} \mathrm{S}$ to $70^{\circ} \mathrm{S}$. As a result, the TIL disappears over the Antarctic in austral winter as reported by Tomikawa et al. (2009). The large latitudinal gradient of the static stability between $60^{\circ} \mathrm{S}$ and $70^{\circ} \mathrm{S}$ is accompanied by the enhanced westerly shear above the tropopause, which forms the polar-night jet in the winter stratosphere.

5 Thus, it is suggested that there is a close relationship between the absence of the TIL and the stratospheric polar vortex in the Antarctic winter.

The vertical gradient of ozone mixing ratio around the tropopause showed similar latitudinal and seasonal variations with the static stability in the $\mathrm{SH}$ extratropics. On the other hand, a small vertical gradient of ozone mixing ratio associated with the Antarctic 10 ozone hole appeared over the Antarctic in austral spring and reached the midlatitudes in a height region of the subvortex, which is located between the tropopause and the bottom of the stratospheric polar vortex. This result indicates that the latitudinal mixing between the midlatitudes and subvortex is active and contributes to the midlatitude ozone loss. At the same time, it is found that the polar-night jet acts as a barrier to 5 confine the ozone-depleted air inside the polar vortex.

The concept of the tropopause inversion layer (TIL) and the extratropical tropopause transition layer (ExTL) has significantly developed our understanding on the extratropical tropopause region in the last decade. Originally these two layers were treated independently, one of which describes the thermodynamic character of the extratropi20 cal tropopause and the other comes from the material distribution. However, vigorous research on the extratropical tropopause demonstrated that they interact with each other through transport/mixing and radiative processes. Further research is still going on in several directions. Satellite observations which cover the whole globe increasingly become higher resolution enough for capturing a sharp vertical structure of the tropopause (e.g., Hegglin et al., 2009). General circulation models with a resolution high enough to resolve the tropopause structure (e.g., Miyazaki et al., 2010a,b) will become more realistic by including interactive chemisty. It is also attempted to assimilate observational data of chemical constituents into forecast models (i.e., chemical data assimilation, Constantinescu et al. (2007)). In addition to these ongoing research, it

\section{ACPD}

10, 19175-19194, 2010

\section{$\mathrm{N}^{2}$ and $d \mathrm{O}_{3} / d z$ around the $\mathrm{SH}$ tropopause}

Y. Tomikawa and T. Yamanouchi




is planned to install a new mesosphere-stratosphere-troposphere (MST) radar and a Rayleigh/Raman lidar at Syowa Station over the Antarctic. The MST radar can measure the three-dimensional wind in the troposphere and lower stratosphere with high vertical and temporal resolutions. The Rayleigh/Raman lidar can obtain a vertical profile 5 of temperature from the troposphere to the mesosphere. By combining these observations with other material observations by ozone, aerosol, and hygrometer sondes, an interplay between dynamic, radiative, and chemical processes around the Antarctic tropopause will be intensively studied.

Acknowledgements. The ozonesonde data were provided by World Ozone and Ultraviolet Ra10 diation Data Centre (http://www.woudc.org/) and Network for the Detection of Atmospheric Composition Change (http://www.ndsc.ncep.noaa.gov/data/). The GFD-DENNOU Library was used for drawing the figures. This work was supported in part by the Center for the Promotion of Integrated Sciences (CPIS) of Sokendai.

\section{References}

Bell, S. W. and Geller, M. A.: Tropopause inversion layer: Seasonal and latitudinal variations and representation in standard radiosonde data and global models, J. Geophys. Res., 113, D05109, doi:10.1029/2007JD009022, 2008. 19176

Bethan, S., Vaughan, G., and Reid, S. J.: A comparison of ozone and thermal tropopause heights and the impact of tropopause definition on quantifying the ozone content of the troposphere, Quart. J. Roy. Meteorol. Soc., 122, 929-944, 1996. 19177, 19179

Birner, T.: Fine-scale structure of the extratropical tropopause region, J. Geophys. Res., 111, D04104, doi:10.1029/2005JD006301, 2006. 19176, 19180, 19181, 19182

Birner, T.: Residual Circulation and Tropopause Structure, J. Atmos. Sci., in press, 2010. 19177, 19178, 19180

Birner, T., Dörnbrack, A., and Schumann, U.: How sharp is the tropopause at midlatitudes?, Geophys. Res. Lett., 29, 1700, doi:10.1029/2002GL015142, 2002. 19176, 19177, 19180

Chen, P.: Permeability of the Antarctic vortex edge, J. Geophys. Res., 99, 20563-20571, 1994. 19183

\section{$\mathrm{N}^{2}$ and $d \mathrm{O}_{3} / d z$ around the $\mathrm{SH}$ tropopause}

Y. Tomikawa and T. Yamanouchi

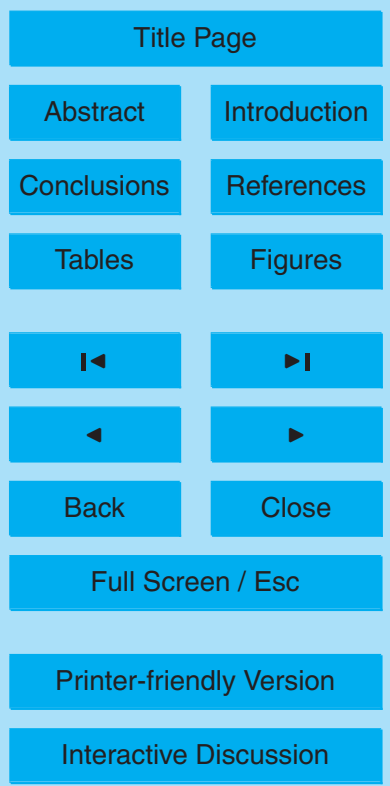


Chen, P., Holton, J. R., O'Neill, A., and Swinbank, R.: Quasi-horizontal transport and mixing in the Antarctic stratosphere, J. Geophys. Res., 99, 16851-16866, 1994. 19184

Constantinescu, E. M., Sandu, A., Chai, T., and Carmichael, G. R.: Ensemble-based chemical data assimilation. I: General approach, Q. J. Roy. Meteorol. Soc., 133, 1229-1243, 2007. 19185

Grise, K. M., Thompson, D. W. J., and Birner, T.: A Global Survey of Static Stability in the Stratosphere and Upper Troposphere, J. Climate, 23, 2275-2292, 2010. 19177, 19181

Haynes, P. and Shuckburgh, E. F.: Effective diffusivity as a diagnostic of atmospheric transport, 2. Troposphere and lower stratosphere, J. Geophys. Res., 105, 22795-22810, 2000. 19183

10 Hegglin, M. I., Boone, C. D., Manney, G. L., and Walker, K. A.: A global view of the extratropical tropopause transition layer from Atmospheric Chemistry Experiment Fourier Transform Spectrometer $\mathrm{O}_{3}, \mathrm{H}_{2} \mathrm{O}$, and CO, J. Geophys. Res., 114, D00B11, doi:10.1029/2008JD009984, 2009. 19178, 19185

Highwood, E. J., Hoskins, B. J., and Berrisford, P.: Properties of the Arctic tropopause, Quart. 15 J. Roy. Meteorol. Soc., 126, 1515-1532, 2000. 19177

Komhyr, W. D., Barnes, R. A., Brothers, G. B., Lathrop, J. A., and Opperman, D. P.: Electrochemical concentration cell ozonesonde performance evaluation during STOIC 1989, J. Geophys. Res., 100, 9231-9244, 1995. 19179

Kunz, A., Konopka, P., Müller, R., Pan, L. L., Schiller, C., and Rohrer, F.: High static stability in the mixing layer above the extratropical tropopause, J. Geophys. Res., 114, D16305, doi: 10.1029/2009JD011840, 2009. 19177, 19180

McIntyre, M. E.: The stratospheric polar vortex and sub-vortex: Fluid dynamics and midlatitude ozone loss, Phil. Trans. Roy. Soc. London, UK, 352, 227-240, 1995. 19183

Miyazaki, K., Sato, K., Watanabe, S., Tomikawa, Y., Kawatani, Y., and Takahashi, M.: Transport and mixing in the extratropical tropopause region in a high vertical resolution GCM. Part II: Relative importance of large-scale and small-scale dynamics, J. Atmos. Sci., 67, 1315-1336, 2010a. 19178, 19185

Miyazaki, K., Watanabe, S., Kawatani, Y., Tomikawa, Y., Sato, K., and Takahashi, M.: Transport and mixing in the extratropical tropopause region in a high vertical resolution GCM. Part I: 30 Potential vorticity and heat budget analysis, J. Atmos. Sci., 67, 1293-1314, 2010b. 19178, 19181, 19185

Pan, L. L., Randel, W. J., Gray, B. L., Mahoney, M. J., and Hintsa, E. J.: Definitions and sharpness of the extratropical tropopause: A trace gas perspective, J. Geophys. Res., 109,

\section{$\mathrm{N}^{2}$ and $d \mathrm{O}_{3} / d z$ around the $\mathrm{SH}$ tropopause}

Y. Tomikawa and T. Yamanouchi

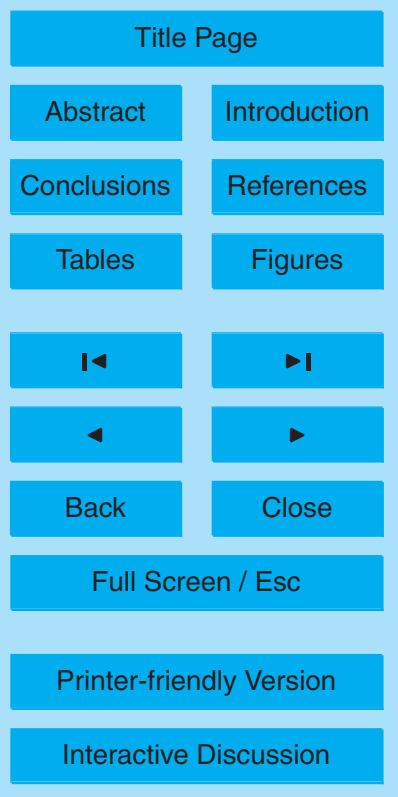


D23103, doi:10.1029/2004JD004982, 2004. 19178

Pan, L. L., Randel, W. J., Gille, J. C., Hall, W. D., Nardi, B., Massie, S., Yudin, V., Khosravi, R., Konopka, P., and Tarasick, D.: Tropospheric intrusions associated with the secondary tropopause, J. Geophys. Res., 114, D10302, doi:10.1029/2008JD011374, 2009. 19184

5 Randel, W. J. and Wu, F.: The polar summer tropopause inversion layer, J. Atmos. Sci., in press, 2010. 19177, 19181

Randel, W. J., Seidel, D. J., and Pan, L. L.: Observational characteristics of double tropopauses, J. Geophys. Res., 112, D07309, doi:10.1029/2006JD007904, 2007a. 19184

Randel, W. J., Wu, F., and Forster, P.: The extratropical tropopause inversion layer: Global observations with GPS data, and a radiative forcing mechanism, J. Atmos. Sci., 64, 44894496, 2007b. 19176, 19177, 19181

Reid, S. J., Rex, M., von der Gathen, P., Fløisand, I., Stordal, F., Carver, G. D., Beck, A., Reimer, E., Krüger-Carstensen, R., de Haan, L. L., Braathen, G., Dorokhov, V., Fast, H., Kyrö, E., Gil, M., Lityñska, Z., Molyneux, M., Murphy, G., O’Connor, F., Ravegnani, F., Varotsos, C., Wenger, J., and Zerefos, C.: A study of ozone laminae using diabatic trajectories, contour advection and photochemical trajectory model simulations, J. Atmos. Chem., 30, 187-207, 1998. 19184

Roscoe, H. K.: Possible descent across the "Tropopause" in Antarctic winter, Adv. Space Res., 33, 1048-1052, 2004. 19177, 19179

20 Rosenlof, K. H. and Holton, J. R.: Estimates of the stratospheric residual circulation using the downward control principle, J. Geophys. Res., 98, 10465-10479, 1993. 19183

Sato, K., Tomikawa, Y., Hashida, G., Yamanouchi, T., Nakajima, H., and Sugita, T.: Longitudinal dependence of ozone recovery in the Antarctic polar vortex revealed by balloon and satellite observations, J. Atmos. Sci., 66, 1807-1820, 2009. 19183

Tomikawa, Y., Sato, K., and Shepherd, T. G.: A diagnostic study of waves on the tropopause, J. Atmos. Sci., 63, 3315-3332, 2006. 19181

Tomikawa, Y., Nishimura, Y., and Yamanouchi, T.: Characteristics of tropopause and tropopause inversion layer in the polar region, SOLA, 5, 141-144, 2009. 19177, 19179, 19181, 19182, 19185

so Wirth, V.: Static stability in the extratropical tropopause region, J. Atmos. Sci., 60, 1395-1409, 2003. 19177

WMO: Meteorology - A three-dimensional science, WMO Bull., 6, 134-138, 1957. 19177

\section{$\mathrm{N}^{2}$ and $d \mathrm{O}_{3} / d z$ around the $\mathrm{SH}$ tropopause}

Y. Tomikawa and T. Yamanouchi






\section{ACPD}

10, 19175-19194, 2010

\section{$\mathrm{N}^{2}$ and $d \mathrm{O}_{3} / d z$ around the $\mathrm{SH}$ tropopause}

Table 1. Ozonesonde data used in this study. $\delta z$ is a vertical resolution. See the text for details.

\begin{tabular}{ccccccc}
\hline Station Name & Longitude & Latitude & Period & No. of Profiles & $\delta z(\mathrm{~m})$ & Data Source \\
\hline South Pole & $24.8^{\circ} \mathrm{W}$ & $90.0^{\circ} \mathrm{S}$ & $12.1999-1.2009$ & 622 & $\sim 50$ & NDACC \\
McMurdo & $166.7^{\circ} \mathrm{W}$ & $77.9^{\circ} \mathrm{S}$ & $8.1986-10.2008$ & 746 & $\sim 25$ & NDACC \\
Neumayer & $8.3^{\circ} \mathrm{W}$ & $70.7^{\circ} \mathrm{S}$ & $3.1992-11.2009$ & 1303 & $\sim 25$ & WOUDC \\
Syowa & $39.6^{\circ} \mathrm{E}$ & $69.0^{\circ} \mathrm{S}$ & $1.2003-9.2009$ & 435 & $\sim 50$ & WOUDC \\
Davis & $78.0^{\circ} \mathrm{E}$ & $68.6^{\circ} \mathrm{S}$ & $4.2006-4.2010$ & 103 & $\sim 50$ & WOUDC \\
Dumont d'Urville & $140.0^{\circ} \mathrm{W}$ & $66.7^{\circ} \mathrm{S}$ & $1.1991-1.2007$ & 407 & $\sim 100$ & NDACC \\
Marambio & $56.7^{\circ} \mathrm{W}$ & $64.2^{\circ} \mathrm{S}$ & $1.2005-5.2010$ & 307 & $\sim 50$ & WOUDC \\
Macquarie Island & $159.0^{\circ} \mathrm{E}$ & $54.5^{\circ} \mathrm{S}$ & $1.2006-4.2010$ & 183 & $\sim 10$ & WOUDC \\
Lauder & $169.7^{\circ} \mathrm{E}$ & $45.0^{\circ} \mathrm{S}$ & $11.1988-12.2008$ & 1167 & $\sim 50$ & WOUDC \\
Broadmeadows & $145.0^{\circ} \mathrm{E}$ & $37.7^{\circ} \mathrm{S}$ & $1.2005-4.2010$ & 245 & $\sim 50$ & WOUDC \\
\hline
\end{tabular}

Y. Tomikawa and

T. Yamanouchi

Title Page

Abstract

Introduction

Conclusions

References

Tables

Figures

14



Back

Full Screen / Esc

Printer-friendly Version

Interactive Discussion 
(a) $\mathrm{N}^{2}$ in 1992-2009 at Neumayer



(b) $\mathrm{N}^{2}$ in 1999-2009 at South Pole

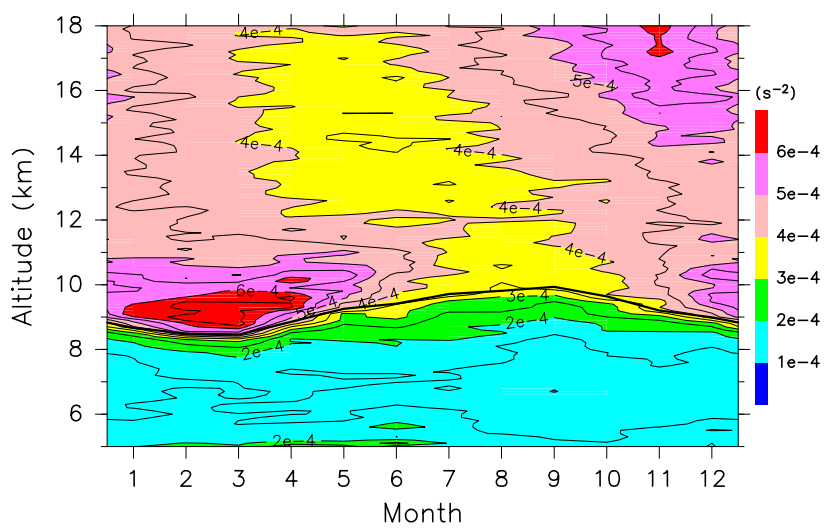

Fig. 1. Seasonal variations of monthly-mean $\mathrm{N}^{2}$ at (a) Neumayer and (b) South Pole in the OTB coordinate. Thick solid lines represent the ozone tropopause. Contour intervals are $0.5 \times 10^{-4} \mathrm{~s}^{-2}$.

\section{ACPD}

10, 19175-19194, 2010

\section{$\mathrm{N}^{2}$ and $d \mathrm{O}_{3} / d z$ around the $\mathrm{SH}$ tropopause}

Y. Tomikawa and

T. Yamanouchi

Title Page

Abstract

Introduction

Conclusions

References

Tables

Figures

14

Back

Full Screen / Esc

Printer-friendly Version

Interactive Discussion 


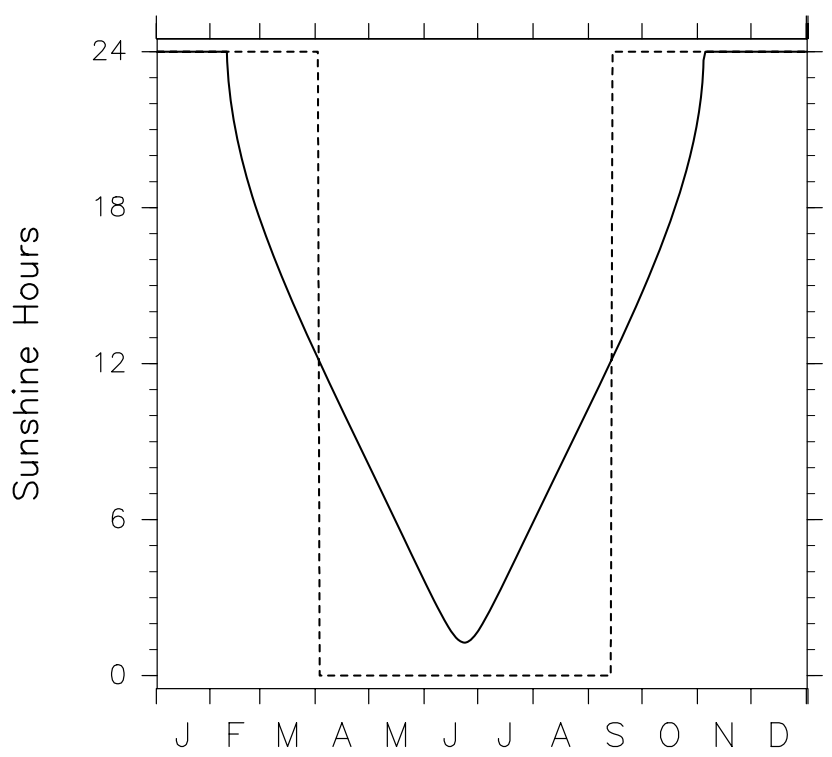

\section{$\mathrm{N}^{2}$ and $d \mathrm{O}_{3} / d z$ around the $\mathrm{SH}$ tropopause \\ Y. Tomikawa and \\ T. Yamanouchi}

Title Page

Abstract

Introduction

Conclusions

References

Tables

Figures

14

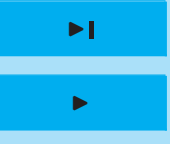

Back

Close

Full Screen / Esc

Printer-friendly Version

Interactive Discussion 


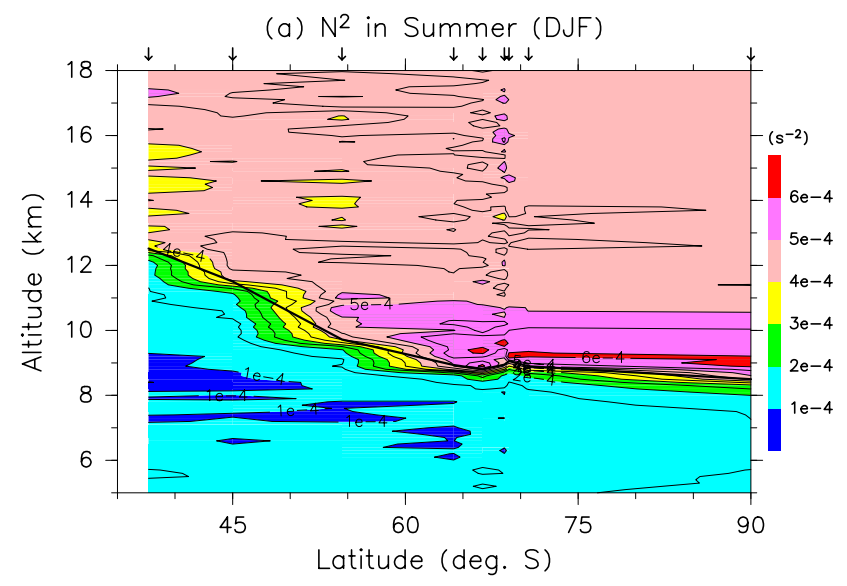

\section{ACPD}

10, 19175-19194, 2010

\section{$\mathrm{N}^{2}$ and $d \mathrm{O}_{3} / d z$ around the $\mathrm{SH}$ tropopause}

Y. Tomikawa and

T. Yamanouchi

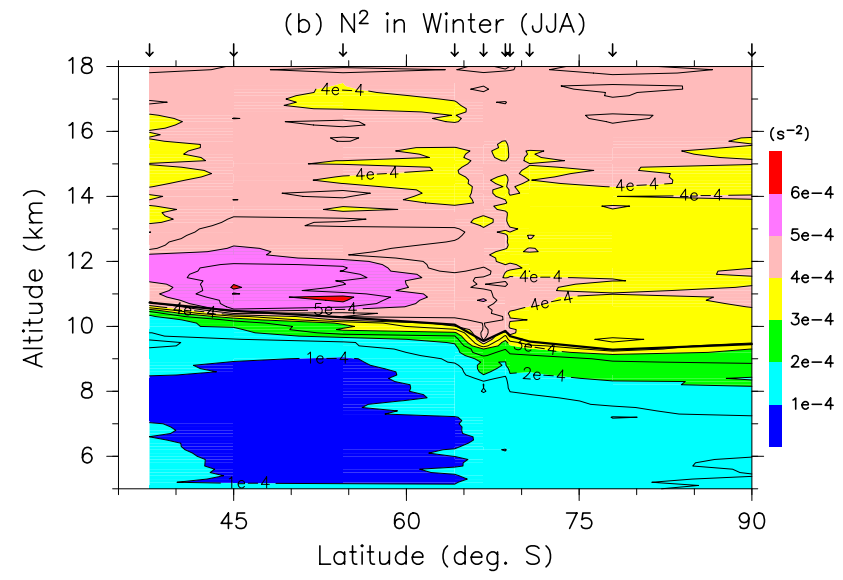

Title Page

Abstract

Introduction

Conclusions

References

Tables

Figures

14

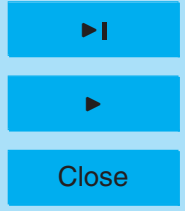

Back

Full Screen / Esc

Fig. 3. Latitude-height sections of seasonal-mean $\mathrm{N}^{2}$ in (a) austral summer (DJF) and (b) winter (JJA) in the OTB coordinate. Thick solid lines represent the ozone tropopause. Contour intervals are $0.5 \times 10^{-4} \mathrm{~s}^{-2}$. Arrows on the top axes represent the station latitudes. 
(a) Ozone Vertical Gradient in 1992-2009 at Neumayer

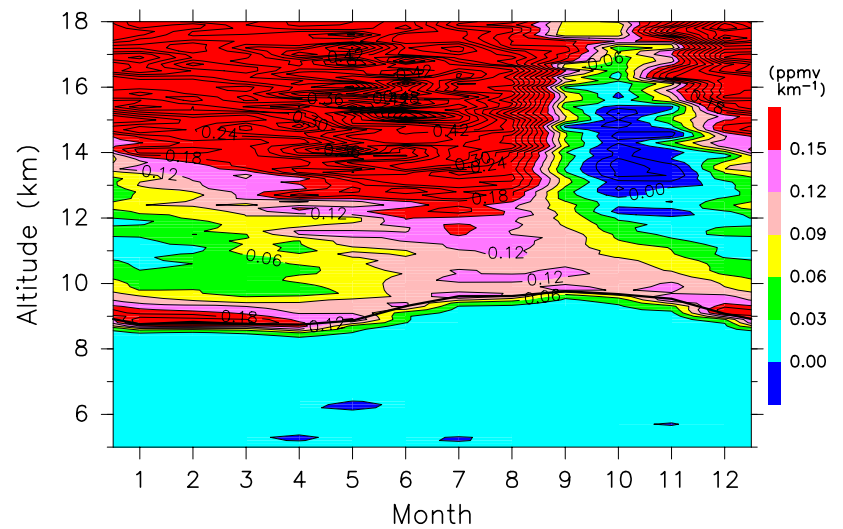

\section{ACPD}

10, 19175-19194, 2010

\section{$\mathrm{N}^{2}$ and $d \mathrm{O}_{3} / d z$ around the $\mathrm{SH}$ tropopause}

Y. Tomikawa and T. Yamanouchi



Fig. 4. Same as Fig. 1 except for the vertical gradient of ozone mixing ratio at (a) Neumayer and (b) Lauder. Contour intervals are $0.03 \mathrm{ppmv} \mathrm{km}^{-1}$.

Title Page

Abstract

Introduction

Conclusions

References

Tables

Figures

14

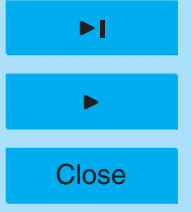

Back

Full Screen / Esc

Printer-friendly Version

Interactive Discussion 
(a) Ozone Vertical Gradient in Winter (JJA)

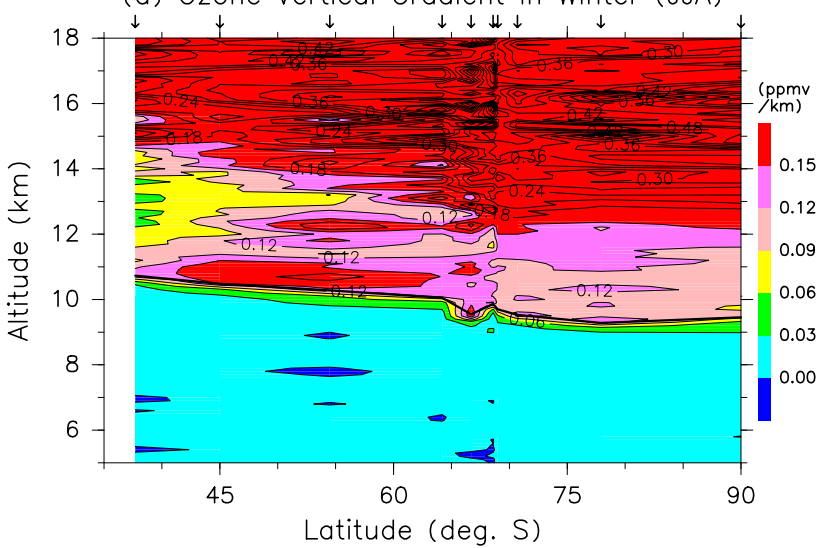

\section{ACPD}

10, 19175-19194, 2010

\section{$\mathrm{N}^{2}$ and $d \mathrm{O}_{3} / d z$ around the $\mathrm{SH}$ tropopause}

Y. Tomikawa and

T. Yamanouchi

Title Page

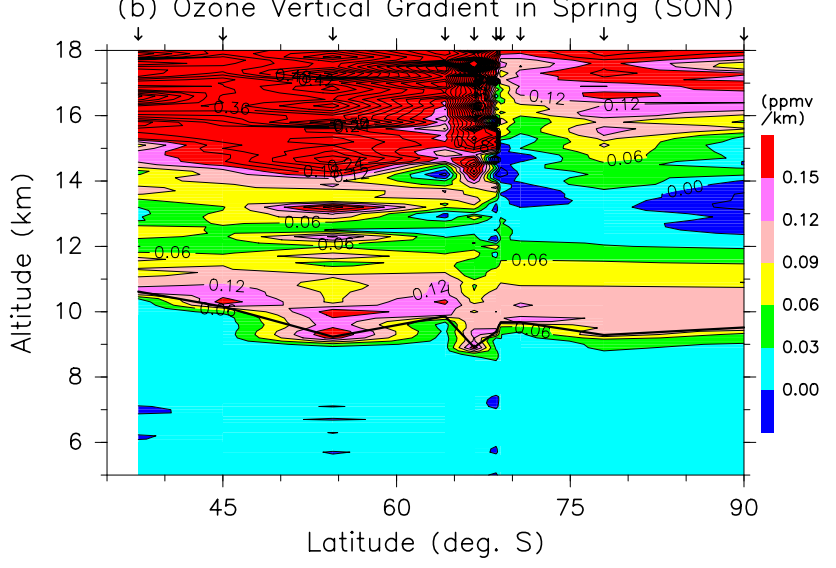

Abstract

Introduction

Conclusions

References

Tables

Figures

14

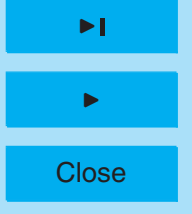

Back

Full Screen / Esc

Printer-friendly Version

Fig. 5. Same as Fig. 3 except for the vertical gradient of ozone mixing ratio in (a) austral winter (JJA) and (b) spring (SON). Contour intervals are $0.03 \mathrm{ppmv} \mathrm{km}^{-1}$.

Interactive Discussion 